\title{
The Sensitivity and Specificity of Saliva Biomarker MMP-9 for Detection Oral Squamous Cell Carcinoma (OSCC)
}

\author{
Dr. Gholamreza Jahanshahi ${ }^{*}$, Dr. Ardeshir Talebi ${ }^{2}$, Dr. Soheila Derisavy ${ }^{3}$ \\ ${ }^{I}$ Full Professor of Oral and Maxilla Facial Pathology, Dept. of Oral and Maxillofacial Pathology, Professor \\ Torabinejad Research Center, School of Dentistry, Isfahan University of Medical Science, Isfahan, Iran \\ ${ }^{2}$ Associated Professor of Pathology, Dept. of pathology, School of Medicine, Isfahan University of Medical \\ Science, Isfahan, Iran \\ ${ }^{3}$ Resident of Oral and Maxilla Facial Pathology, Dept. of Oral and Maxillofacial Pathology, Professor \\ Torabinejad Research Center, School of Dentistry, Isfahan University of Medical Science, Isfahan, Iran \\ *Corresponding Author: Dr. Gholamreza jahanshahi, Full Professor of Oral and Maxilla Facial \\ Pathology, Dept. of Oral and Maxillofacial Pathology, Professor Torabinejad Research Center, School of \\ Dentistry, Isfahan University of Medical Science, Isfahan, Iran, Email: jahanshahi@dnt.mui.ac.ir
}

\begin{abstract}
Introduction: Oral squamous cell carcinoma (OSCC) is one of the prevalent and lethal types of all malignancies. Like other malignancies early diagnosis is important. So, salivary biomarkers evaluation as a noninvasive, simple and rapid test may be qualified. The aim of this study was to investigate the relationship between salivary MMP-9 concentration and its tissue expression in patients with OSCC and assessment accuracy (sensitivity \& specificity) of salivary MMP9 bio marker in revealing OSCC.
\end{abstract}

Materials and Methods: Saliva samples were collected from 66 patients with primary diagnosis of OSCC and 66 healthy age and gender matched persons. The unstimulated saliva was collected by spitting method. Salivary concentration and tissue expression of MMP-9 were evaluated using ELISA and immunohistochemistry assays, respectively. Data were analyzed by T-Test, Chi-square and ANOVA tests with the confidence interval of $95 \%$.

Results: A significant increase in salivary concentration Of MMP-9 was evident in OSCC patients in comparison to healthy persons (P-value <0.05). There was a positive and significant correlation between salivary concentration of MMP-9 and its tissue expression and overall this trend was more obvious in male patients. (Pearson Correlation $=0.459$, P-value $<0.001$ ). Sensivity of salivary expression test for $M M P-9=$ $71 \%$, Positive Predictive Value $=78 \%$, Specificity $=80 \%$, Negative Predictive Value $=74 \%$

Conclusion: Salivary evaluation of MMP-9 concentration may be a valuable tool to detect OSCC in early stages and perhaps a useful facility for screening.

Keywords: Saliva, MMP-9, Oral Squamous Cell Carcinoma, Immunohistochemistry, Sensitivity (Sen), Specificity (Sp), Positive Predictive Value (PPV), Negative Predictive Value (NPV).

\section{INTRODUCTION}

Within the past 10 years, the application of saliva as a diagnostic tool has gained considerable attention and well-accepted method. As a diagnostic fluid, saliva offers superiority over serum due to both noninvasive collection methods and a cost-effective approach for screening of large populations. In addition, collection of saliva offers a reduced risk of infection compared to the serum sampling (1). Early detection of disease plays a significant role in successful treatment. In most cases of various diseases, early diagnosis leads to a greater survival rate with a reduced chance of the disease recurrence. Successful monitoring of a disease, especially in its early stage, may also reduce any severe impacts on a patient's health or help to prevent and/or delay succeeding complications. Following disease progression, and monitor post-treatment therapeutic effect through a noninvasive method is one of the primary objectives in the field of healthcare research. Saliva, a multi-constituent oral fluid that can be collected through noninvasive methods, has considerable potential 
for the surveillance of general health. Human saliva contains many kinds of proteins and peptides, each of them carries several significant biological functions.

With the advancement of novel technological means (such as metabolomics, genomics and proteomics), saliva, as a clinical tool, has got a more and more attractive option because of its ability to mirror both oral and systemic health conditions. But in order for saliva-based diagnostics to be useful, two prerequisites must be fulfilled: (A) discovering biomarkers for various diseases among the complicated composition of saliva, and (B) evaluating the sensitivity and specificity of biomarkers through a series of studies (2).

Detection of OSCC is currently based on thorough clinical oral examination combined with biopsy for a histological exam, if an abnormal area is detected. The location from which the biopsy sample is taken is crucial for histopathological verification of the oral cancer. However, selecting the right location may be difficult because of the non-uniform appearance of cancerous and precancerous lesions (3). Most OSCC cases are detected when the cancer has developed into the advanced stages. Some lesions are difficult to detect in a general examination if located in sightless regions. Delay of detection may account for the high morbidity rate of OSCC. Usually early OSCC is asymptomatic so pain and burning sensation may not develop until the neoplasm progress to advance stages (4).

1. The scientific study of the set of metabolites presents within an organism, cell, or tissue.

2. The branch of molecular biology concerned with the structure, function, evolution, and mapping of genomes.

3 . The study of proteomes and their function. A proteome is a set of proteins produced in an organism, system or biological context.

As mentioned saliva is a multi-constituent fluid capable of mirroring both oral and systemic health conditions. Salivary analysis has been shown to be a useful diagnostic tool for other malignancies, such as breast, lung, and pancreatic cancers and even for Sjogren's syndrome (5-11). In extension of author previous study (28) this time we did the same but with more participants emphasize on sensivity and specificity of saliva assessment for MMP-9 concentration.

\section{Material ANd Methods}

\subsection{Patients}

This study was performed in Esfahan University of Medical Sciences. Patients who were referred to Esfahan dental school with primarily diagnosed of oral squamous cell carcinoma (OSCC) were participated in the study.

Patients who had been biopsied or received any treatment prior to saliva collection were excluded from the study. The control group included healthy subjects with identical age and gender with study group.

\subsection{Saliva Collection}

Saliva can be collected in two ways: "unstimulated" or "stimulated". Unstimulated saliva is collected by draining or drool, spitting, suction, or swab. Stimulated saliva is collected by providing the patients with a stimulant agent, such as citric acid, paraffin, or a gum base. With stimulated collection, saliva is obtained primarily from the parotid gland, whereas unstimulated (resting) saliva is produced primarily by the submandibular gland, with minor contributions from the parotid and sublingual glands. In addition, stimulation of saliva production decreases the concentration of small molecules, changing the total composition of the analyzed saliva in favor of larger molecules. Thus, unstimulated saliva is more favorable for biomarker analysis and has been utilized in most diagnostic studies (12-15).

Unstimulated saliva collected from 66 patients with primary diagnosis of OSCC and 66 healthy subjects using the spitting technique. In this technique patients were asked to maintain the saliva for 5 to 15 minutes and spit it every 60 seconds. Patients were instructed to prohibit brushing, smoking, eating, and drinking 90 minutes prior to saliva sampling and one milliliter of saliva collected for each patient.

\subsection{MMP-9 Concentration in Saliva}

We used Human MMP-9 ELISA Kit made by BOSTER BIOLOGICAL TECHNOLOGY Co., Inc. USA. Booster's human MMP-9 ELISA Kit was based on standard sandwich enzyme-linked immune-sorbent assay for specific detection of monoclonal antibodies by biotinylated. The test sample and biotinylated detection antibodies were added to the wells subsequently and then followed by washing with TBS buffer. AvidinBiotin-Peroxidase Complex was added and unbound conjugates were washed away with 
TBS buffer. HPR substrate TMB was used to visualize HPR enzymatic reaction. TMB was catalyzed by HPR to produce a blue color produce that changed into yellow after adding acidic stop solution. The density of yellow is proportional to the human MMP-9 amount of sample capture in plate.

We added samples and standards and incubated the plate at $37^{\circ} \mathrm{C}$ for 90 minutes. Then we added biotinylated antibodies and incubated the plates at $37^{\circ} \mathrm{C}$ for $60 \mathrm{~min}$. washed plates 3 times with $0.01 \mathrm{M}$ TBS. We added ABC working solution and incubated the plates at $37^{\circ} \mathrm{C}$ for 30 minutes and washed 5 times with $0.01 \mathrm{M}$ TBS. We added TMB color developing agent and incubated the plates at $37^{\circ} \mathrm{C}$ for $25-30 \mathrm{~min}$. Finally, added TMB stop solution and read by Start Fax made USA.

\subsection{Tissue Sample Preparation}

Following saliva collection, patients with primary clinical diagnosis of OSCC were underwent a biopsy to establish the diagnosis. After 24 hours' fixations in 10\% formalin and ordinary tissue processing for samples, the specimens were embedded in paraffin blocks and were cut into $3 \mu$ slices. One of the slices was used in H\&E staining and the other for immunohistochemistry (IHC) staining. Slices were mounted on Poly-L-lysine-coated slides. Briefly, the sections were dewaxed with xylene, and rehydrated in graded ethanol. Prepared slides were put in Hematoxylin and Eosin staining. Then the slides were rinsed with water and were dehydrated in gradual alcohol. For IHC staining, slides were dehydrated and immersed in EDTA (Novacastra, Germany) for 20 minutes (95 centigrade degree). Slides were remained in cold condition for 30 minutes and rinsed in hydrogen peroxidase. Then slides were preserved with the secondary antibody for 30 minutes, conjugated using the conjugation solution (Novacastra, Germany) for 30 minutes and finally rinsed in DAB solution (Novacastra, Germany) for 5 minutes. Then the slides were rinsed with water and stained with $\mathrm{H} \& \mathrm{E}$ staining.

\subsection{MMP-9 Concentration in Tissue Samples}

The stained tissue samples were evaluated under light microscope with 40×magnitude. Two unaware pathologists counted the number of stained cells and degree of staining in 5 random fields to calculate the SID criteria. The number of stained cells was categorized into 1: $0-25 \%$;
2: 26-50\%; 3: 51-75\%; and 4: 76-100\%. In addition, the degree of staining was categorized into 0: no staining; 1: very low; 2 : low; 3 : moderate; 4: high. The SID criteria calculated with multiplying the number of stained cells with degree of staining.

\subsection{Statistical Analysis}

Data were entered in to SPSS software version 11.5 (Chicago, IL). In order to analyze data, $t$ test, chi-square, and ANOVA tests were performed with the confidence interval of $95 \%$.

\section{RESULTS}

In the current study 66 (49 males and 17 females) healthy and 66 (49 males and 17 females) patients with OSCC participated. The mean age and gender distribution of both groups was identical. Based on the KolmogorovSmirnov test the data were distributed normally (P-value > 0.05). The distribution of study variables based on gender is presented in Table1. According to the independent sample $\mathrm{T}$ - test, no significant difference observed between males and females regarding age $(\mathrm{P}-$ value $>0.05)$. However, a significant difference between two genders observed regarding salivary concentration of MMP-9 (P-value < $0.05)$.

Table1. Distribution of study variables based on gender

\begin{tabular}{|c|c|c|c|c|c|}
\hline Variable & Gender & $\mathbf{N}$ & Mean & $\begin{array}{l}\text { Standard } \\
\text { deviation }\end{array}$ & $\begin{array}{c}\text { P- } \\
\text { Value }\end{array}$ \\
\hline \multirow{2}{*}{$\begin{array}{l}\text { Salivary } \\
\text { MMP-9 } \\
\text { (control } \\
\text { group) }\end{array}$} & Female & 17 & 6889.53 & 1752.98 & \multirow[b]{2}{*}{0.155} \\
\hline & Male & 49 & 7922.52 & 2826.44 & \\
\hline \multirow{2}{*}{$\begin{array}{l}\text { Salivary } \\
\text { MMP-9 } \\
\text { (study } \\
\text { group) }\end{array}$} & Female & 17 & 10244.91 & 3381.89 & \multirow[b]{2}{*}{0.012} \\
\hline & Male & 49 & 12781.04 & 3542.25 & \\
\hline \multirow{2}{*}{$\begin{array}{l}\text { Tissue } \\
\text { MMP-9 } \\
\text { (study } \\
\text { group) }\end{array}$} & Female & 17 & 9.45 & 1.45 & \multirow[b]{2}{*}{0.050} \\
\hline & Male & 49 & 10.45 & 3.08 & \\
\hline \multirow{2}{*}{$\begin{array}{l}\text { Age (both } \\
\text { group) }\end{array}$} & Female & 17 & 66.88 & 10.98 & \multirow[b]{2}{*}{0.879} \\
\hline & Male & 49 & 66.24 & 10.48 & \\
\hline
\end{tabular}

In order to investigate the correlation between salivary concentration of MMP-9 and its tissue expression, Pearson test was performed. The outcome of the mentioned analysis revealed a significant association between these two concentrations (Pearson Correlation $=0.459, \mathrm{P}$ value $=0.000) .($ Graph1 $)$. 


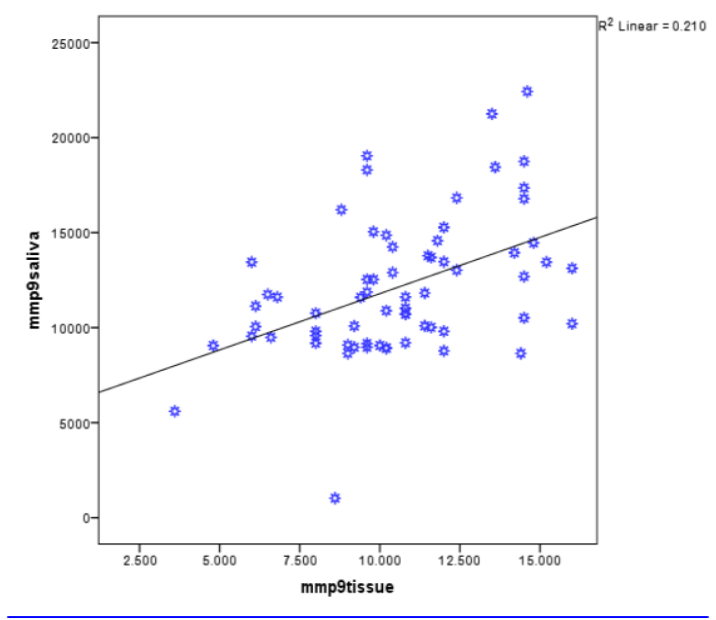

Graph1. Tissue and salivary concentration of MMP-9

For evaluation of the effect of gender (male and female) and group (study and control) univariate Analysis of Variance was performed. The results of this analysis revealed a significant difference between two genders $(\mathrm{P}$-value $=$ $0.000)$ and groups (P-value $=0.000)$. In addition, no significant interaction was found between two variables (gender and group) (Pvalue $=0.879)$. According to gathering data, Table $2 \times 2$ was complete (Table 2 ).

Table2. Table $2 \times 2$ (Sensivity and specificity)

\begin{tabular}{|c|c|c|c|l|}
\hline Total & Control & Study & & \\
\hline 60 & $13(\mathrm{~T}-)$ & $47(\mathrm{~T}+)$ & Positive & Pathology \\
\hline 72 & $53(\mathrm{~N}+)$ & $19(\mathrm{~N}-)$ & Negative & Diagnosis \\
\hline 132 & 66 & 66 & Total & \\
\hline
\end{tabular}

$(T+)$ : True positive, $(T-)$ : False positive, $(N+)$ : True negative, (N-): False negative

Salivary expression of MMP-9 Sensitivity $=71 \%$, Positive Predictive Value (PPV) $=78 \%$, Specify $=80 \%$, Negative Predictive Value. (NPV) $=74 \%$

\section{DISCUSSION}

The saliva is in direct contact with the oral mucosa and cancerous lesions, the screening and detection of OSCC lesions in early stage, using saliva may be a promising method to avoid wasting time. Current therapy for OSCC is based on traditional stage-predicting guides (mostly the TNM criteria) and histopathological grading. An important advancement in salivary diagnostics is the development of omics-based biomarkers. The term saliva omics was coined to reflect the rapid development of translational and clinical tools based on salivary biomarkers (16-18).

In biomarker research, the sensitivity and specificity of a marker must be determined in each study. Sensitivity is the true-positive rate, which is described by the percentage of the total number of people with the disease that test positive. Specificity is the true-negative rate, which measures the proportion of individuals that test negative for the disease that actually do not have the disease (3).

In 2008, 1166 salivary proteins were initially identified in a National Institute of Dental and Craniofacial Research (NIDCR)-funded project that sought to catalog and annotate the human salivary proteome. This project was an essential first step for saliva to be clinically useful in disease diagnosis and health monitoring. The majority of the proteins are synthesized and subsequently secreted into the oral cavity by the salivary gland acinar cells. This observation suggests that proteomics constituents of saliva are products of the salivary glands, which may be subject to internal and external factors. Consequently, the salivary proteome has been used for identifying biomarkers for both local and distant diseases (19-20).

The matrix metalloproteinase (MMP) may play a key role in cancer development, as they cause degradation of the extracellular matrix and basement membrane. MMPs have been studied as potential cancer biomarkers and associated with tumor invasion and metastasis (21). In 2011, Stott-Miller et al. determined whether salivary concentrations of the most highly differentially expressed MMPs could be used as diagnostic aid. The concentrations of MMP1 and MMP3 were tested in saliva samples from100 subjects (60 primary OSCC cases, 15 dysplasia cases, and 25 controls). The protein concentrations were higher in the saliva from OSCC patients compared to the saliva from cancer-free controls (22).

Most of the previous studies were aimed to evaluate the presence of MMP-9 in tissues and few studies evaluate the serum or salivary concentration of MMP-9. Wang et al investigated the serum concentration of MMP-9 in patients with Head and Neck Carcinoma (HNSCC). They found that the MMP-9 was significantly higher in the serum of patients when compared with control individuals (23).

Cheng et al found that the serum concentration of MMP-9 was significantly higher in patients with nasopharynx SCC in comparison to healthy individuals (24). Patel et al. found that the changes in serum concentration of MMP-9 were 
in line with the progress of patients' treatment (25).

The aims of the current study were to investigate the relationship between salivary concentration of MMP-9 and its tissue expression in patients and assessment sensitivity and specificity in salivary test for detection of OSCC.

Based on findings of the present study, the salivary concentration of MMP-9 was significantly higher in patients with OSCC when compared with healthy people. In accordance with our findings, Shpitzer et al (2007) evaluated the salivary concentration of 25 patients with OSCC and 25 healthy - age and gender-matched individuals and found significant increase in MMP-9 concentration in saliva of OSCC patients (26). In addition, Shpitzer et al (2009) performed another study again and found significant increase in salivary concentration of MMP-9 in 19 patients with $\operatorname{OSCC}(2)$.

In the current study the unstimulated saliva was collected with the spitting technique. Shpitzer $e t$ al (2009) were also used this method. In the current study individuals in control group were adjusted according to their age and gender with the patients. Similar to our study, Shpitzer et al, 2009), (Shpitzer et al, 2007) were also matched the age and gender of their participants in study and control groups. In addition, Shpitzer et al. (2007) found that the salivary assessment of MMP-9 concentration has high sensitivity (100\%) and specificity (79\%); in our study with more participants, sensitivity and specificity were calculated $(71 \%)$ and $(80 \%)$ respectively, along with the results of the Shpitzer et al studies which both revealed strong relationship between tissue and salivary concentration of MMP-9. In our study the salivary concentration of MMP-9 was also significantly higher in patients with OSCC when compared with healthy people. The results of the present study described that salivary concentration of MMP-9 could be a promising means to diagnose OSCC. It could be concluded that according to results of the present study, salivary evaluation of MMP-9 concentration could be a valuable tool to detect OSCC may be in early stage and perhaps a useful marker for screening. It should be mentioned here that one of the limitations of the current study was the lack of knowledge regarding the stage of tumor. It was due to the deficiency of patient's documents. In case of knowing stage of tumor, we may be able to evaluate the changes of salivary concentration of MMP-9 to predict the stage of OSCC. Hence, it is recommended to consider mentioned data in future studies. While considering the stage of the OSCC.

\section{REFERENCES}

[1] Liu J, Duan Y. Saliva: a potential media for disease diagnostics and monitoring. Oral Oncol. 2012; 48(7):569-77.

[2] Lee YH, Wong DT. Saliva: an emerging biofluid for early detection of diseases.Am J Dent 2009; 22(4):241-8.

[3] MahaYakob, Laurel Fuentes, Marilene B. Wang, Elliot Abemayor, and David T.W. Wong. Salivary biomarkers for detection of oral squamous cell carcinoma - current state and recent advances Curr Oral Health Rep. 2014 June 1; 1(2): 133-141. doi:10.1007/s40496014-0014-y.

[4] Markopoulos AK. Current aspects on oral squamous cell carcinoma. Open Dent J. 2012; 6:126-130. [PubMed: 2293066]

[5] Bigler LR, Streckfus CF, Copeland L, Burns R, Dai XL, Kuhn M, Martin P, Bigler SA. Thepotential use of saliva to detect recurrence of disease in women with breast carcinoma. Journal of Oral Pathology \& Medicine. 2002; 31 (7):421-431. [PubMed: 12165061]

[6] Zhang L, Xiao H, Zhou H, Santiago S, Lee JM, Garon EB, Yang JP, Brinkmann O, Yan XM, AkinD, Chia D, Elashoff D, Park NH, Wong DTW. Development of transcriptomic biomarker signature in human saliva to detect lung cancer. Cellular and Molecular Life Sciences. 2012; 69(19):3341-3350. [PubMed: 22689099]

[7] Xiao H, Zhang L, Zhou H, Lee JM, Garon EB, Wong DTW. Proteomic Analysis of Human Salivafrom Lung Cancer Patients Using TwoDimensional Difference Gel Electrophoresis and Mass Spectrometry. Molecular \& Cellular Proteomics. 2012; 11(2)

[8] Gao K, Zhou H, Zhang L, Lee JW, Zhou Q, Hu S, Wolinsky LE, Farrell J, Eibl G, Wong DT. Systemic Disease-Induced Salivary Biomarker Profiles in Mouse Models of Melanoma and Non-Small Cell Lung Cancer. Plos One. 2009; 4(6)

[9] Hu S, Gao K, Pollard R, Arellano-Garcia M, Zhou H, Zhang L, Elashoff D, KallenbergCG,Vissink A, Wong DT. Preclinical validation of salivary biomarkers for primary Sjegren'ssyndrome. Arthritis Care Res (Hoboken). 2010; 62 (11):1633-1638. [PubMed: 20617533] 
[10] Sugimoto M, Wong DT, Hirayama A, Soga T, Tomita M. Capillary electrophoresis massspectrometry-based saliva metabolomics identified oral, breast and pancreatic cancerspecificprofiles. Metabolomics. 2010; 6 (1):7895. [PubMed: 20300169]

[11] Lau C, Kim Y, Chia D, Spielmann N, Eibl G, Elashoff D, Wei F, Lin YL, Moro A, Grogan T,Chiang S, Feinstein E, Schafer C, Farrell J, Wong DT. Role of pancreatic cancer-derived exosomes in salivary biomarker development. J Biol Chem. 2013; 288 (37):2688826897.[PubMed: 23880764]

[12] de Almeida, PeV; Grégio, AM.; Machado, MA.; de Lima, AA.; Azevedo, LR. Saliva composition and functions: a comprehensive review. J Contemp Dent Pract. 2008; 9 (3):7280. [PubMed:18335122]

[13] . Dodds MWJ, Johnson DA, Yeh CK. Health benefits of saliva: a review. Journal of Dentistry. 2005; 33 (3):223-233. [PubMed: 15725522]

[14] Mohamed R, Campbell JL, Cooper-White J, Dimeski G, Punyadeera C. The impact of salivacollection and processing methods on CRP, IgE, and Myoglobin immune assays. ClinTrans Med. 2012; 1 (1):19. [PubMed: 23369566]

[15] . Principe S, Hui ABY, Bruce J, Sinha A, Liu FF, Kislinger T. Tumor-derived exosomes and microvesicles in head and neck cancer: Implications for tumor biology and biomarker discovery. Proteomics. 2013; 13 (10-11):16081623. [PubMed: 23505015]

[16] Rusthoven K, Ballonoff A, Raben D, Chen C. Poor prognosis in patients with stage I and II oral tongue squamous cell carcinoma. Cancer. 2008; 112 (2):345-351. [PubMed: 18041071]

[17] Anneroth G, Batsakis J, Luna M. Review of the literature and a recommended system of malignancy grading in oral squamous cell carcinomas. Scand J Dent Res. 1987; 95 (3):229-249. [PubMed: 3299675]

[18] Wong DT. Salivaomics. J Am Dent Assoc. 2012; 143 (10 Suppl):19S-24S. This paper coined the term salivaomics to reflect the important advancements in salivary diagnostics through the development of omics-based biomarkers. [PubMed: 23034834]
[19] Denny P, Hagen FKetal. The proteomes of human parotid and submandibular/sublingualgland saliva collected as the ductal secretions. Journal of Proteome Research. 2008; 7 (5):1994-2006. [PubMed: 18361515]

[20] Bonne NJ, Wong DTW. Salivary biomarker development using genomic, proteomic and metabolomic approaches. Genome Medicine. 2012; 4

[21] Sorsa T, Tjaderhane L, Salo T. Matrix metalloproteinases (MMPs) in oral diseases. Oral Diseases. 2004; 10 (6):311-318. [PubMed: 15533204]

[22] Stott-Miller M, Houck JR, Lohavanichbutr P, Mendez E, Upton MP, Futran ND, Schwartz SM, Chen C. Tumor and Salivary Matrix Metalloproteinase Levels Are Strong Diagnostic Markers of Oral Squamous Cell Carcinoma. Cancer Epidemiology Biomarkers \& Prevention. 2011; 20 (12):2628-2636.

[23] Wang WL, Cheng WL, Yeh YC, Lee CT, Chang CY, Lin JT, et al. Concomitantly elevated serum matrix metalloproteinases 3 and 9 can predict survival of synchronous squamous cell carcinoma of the upper aerodigestive tract. Mol Carcinogen. 2013 Jun; 52(6):438-45.

[24] Cheng, D., Kong, H., Li, Y. Prognostic value ofinterleukin-8 and MMP-9 in nasopharyngeal carcinoma Eur Arch Otorhinolaryngology. 2014, 271(3):503-9.

[25] Patel BP1, Shah SV, Shukla SN, Shah PM, Patel PS. Clinical significance of MMP-2 and MMP-9 in patients with oral cancer. Head Neck. 2007 Jun; 29(6):564-72.

[26] Shpitzer T, Bahar G, Feinmesser R, Nagler RM. A comprehensive salivary analysis for oral cancer diagnosis. J Cancer Res Clin Oncol. 2007 Sep; 133(9):613-7.

[27] Shpitzer T, Hamzany Y, Bahar G, Feinmesser R, Savulescu D, Borovoi I, et al. Salivary analysis of oral cancer biomarkers. Br J Cancer. 2009 Oct 6; 101(7):1194-8.

[28] Jahanshahi Gh,Nazemi L,Ardeshir T.Salivary concenteration of MMP-9 in comparsion with tissue expersion in patients with oral squamous cell carcinoma. Int J of current research.2016 may 8:30496-501

Citation: Gholamreza Jahanshahi, Ardeshir Talebi, Soheila Derisavy, The Sensitivity and Specificity of Saliva Biomarker MMP-9 for Detection Oral Squamous Cell Carcinoma (OSCC). ARC Journal of Cancer Science 2018; 4(2):25-30. DOI:dx.doi.org/10.20431/2455-6009.0402006.

Copyright: (C) 2018 Authors. This is an open-access article distributed under the terms of the Creative Commons Attribution License, which permits unrestricted use, distribution, and reproduction in any medium, provided the original author and source are credited. 